OPEN ACCESS

Edited by:

Jun Wang,

University of Wisconsin-Madison,

United States

Reviewed by:

Hui Cheng,

City University of Hong Kong,

Hong Kong

Claudio Tenreiro,

University of Talca, Chile

*Correspondence:

Shasha Yin

ysszjkong@163.com

Specialty section: This article was submitted to

Nuclear Energy,

a section of the journal

Frontiers in Energy Research

Received: 23 March 2018

Accepted: 27 April 2018

Published: 22 May 2018

Citation:

Yin S, Tian Y, Qiu S, Tian Y, Fang H, Huang $W$ and Chen $Z$ (2018) Accident

Process and Core Thermal Response

During a Station Blackout Initiated Study for Small Modular Reactor.

Front. Energy Res. 6:43.

doi: 10.3389/fenrg.2018.00043

\section{Accident Process and Core Thermal Response During a Station Blackout Initiated Study for Small Modular Reactor}

\author{
Shasha Yin ${ }^{1 *}$, Yajing Tian ${ }^{1}$, Suizheng Qiu ${ }^{2}$, Ye Tian ${ }^{1}$, Huawei Fang ${ }^{1}$, Wei Huang ${ }^{1}$ and \\ Zhihui Chen ${ }^{1}$
}

${ }^{1}$ Science and Technology on Reactor System Design Technology Laboratory, Nuclear Power Institute of China, Chengdu, China, ${ }^{2}$ School of Nuclear Science and Technology, Xi'an Jiaotong University Xi'an, Shanxi, China

Interest in evaluation of reactor response and off-site consequences following beyond design basis accidents has significantly increased after Fukushima. Considering the inherent system safety of nuclear plants, experts begin to refocus on the development of small and medium nuclear reactors (SMRs). Based on proven and widely utilized traditional pressurized water reactor (PWR) technology, there are many kinds of small modular reactor design concepts, which are actively being developed in the USA, China, Japan, Russia, Korea, and other countries. But due to the significant differences between the traditional distributed arrangement and integrated arrangement of SMRs, the variation trend of key parameters may be different during normal operation or accident process. Hence, in this paper, we simulated the small modular reactor severe accident by MELCOR. This paper summarizes the core thermal hydraulic response for a hypothetical severe accident caused by station blackout at a small modular reactor using MELCOR. Analytical results for temperature distribution of the fuel pellets, the fuel cladding, flow rate of the coolant, and hydrogen mass changing over time are presented. The analyses are focused on safety assessment of the reactor core for severe accidents and are a part of the overall evaluation of safety features of the small modular reactor for residual risk posed by severe accidents.

Keywords: SMR, core degradation, melting materials immigration, severe accident, MELCOR

\section{INTRODUCTION}

After several severe accidents, such as in Three Mile Island, Chernobyl, and Fukushima, the safety has become the public focus. After the Fukushima accident, experts begin to refocus on the development of small and medium nuclear reactors (SMRs) (Shropshire, 2011), considering the inherent system safety of nuclear plants. Based on the proven and widely utilized traditional pressurized water reactor (PWR) technology, there are many kinds of small modular reactor design concepts, which are actively being developed in the USA, China, Japan, Russia, Korea, and other countries. The USA has basically completed the design of mPower (Halfinger and Haggerty, 2012), NuScale (Johnson et al., 2009; Ingersoll et al., 2014) and W-SMR (Fetterman et al., 2011). Korea has finished the design of SMART (Chang et al., 2000; Bae et al., 2001; Kim et al., 2011) and analyzed 
the system safety. The international co-operations also presented the concept of IRIS (Ricotti et al., 2002; Carelli, 2003; Carelli et al., 2004); meanwhile, the structure designs in other countries are ongoing as well. China has also carried out the related research and development (R\&D) work. Accordingly, in this paper, we choose the SMR as the research object.

Before focusing on SMRs, we should strictly evaluate the safety of SMRs first, before its commercialization (Yin et al., 2014). Especially after the Fukushima accident, attention has been paid to the severe accident prevention and mitigation measures. There are many differences during the severe accident process between the small modular reactor and the traditional large-scale PWR because of the differences in structure and design issues for both reactors. Therefore, focusing on severe accident of small modular reactor and understanding the severe accident process and mechanism are the necessary foundation for the development of small modular reactor severe accident prevention and mitigation measures.

Based on the traditional PWR technology, core degradation, melting materials migration and clad oxidation are all priority research questions (Wang et al., 2014). Currently, SMRs mainly adopt a set of passive safety devices for mitigating the effects of severe accidents (Yin et al., 2016). However, due to the significant differences between the traditionally distributed arrangement and integrated arrangement of SMRs, the variation trend of key parameters may be different during normal operation or accident process. Hence, this article specially focusses the station blackout (SBO) accident for SMRs. Simulated the cladding and fuel pellets failure mode for radial and axial sections in the process of core melt. We calculated the SBO accident; analytical results of temperature distribution of the fuel pellets, the fuel cladding, flow rate of the coolant, and hydrogen mass changing over time are presented. The analyses are focused on safety assessment of the reactor core for severe accidents and are a part of the overall evaluation of safety features of the small modular reactor for residual risk posed by severe accidents.

\section{ANALYSIS MODEL}

\section{Brief Description of MELCOR Code}

MELCOR is a fully integrated, engineering-level computer code that models the progression of severe accident in light water reactor nuclear power plant (Gauntt et al., 1998). MELCOR is executed in two parts, MELGEN and MELCOR (Gauntt et al., 2000a,b). The relationships between MELGEN and MELCOR are shown in Figure 1. MELGEN is also composed of a number of different packages, such as COR, $\mathrm{CVH}$, and FL., and each of the models represents a different portion of the accident phenomenology or program control.

Abbreviations: ACC, accumulators; ADS, automatic depressurization system; CMT, core makeup tank; IRWIST, in-containment refueling water storage tank; RCS, reactor coolant system; PXS, passive core cooling system; PRHRS, passive residual heat removal heat exchange; PWR, pressurized water reactor; R\&D, research and development; SBO, station blackout; SMRs, small and medium nuclear reactors; $\mathrm{SG}$, stream generators.
The major inputs are specified in MELGEN, which are also processed and checked for the parameters. MELCOR is mainly responsible for transient calculation based on the input of MELGEN.

\section{Nodalization of China SMR Primary System}

The nodalization of the severe accident analysis model for China SMR is shown in Figure 2. The major equipment are modeled as control volumes, which contain energy and mass, such as steam generator, pressurizer, core makeup tank (CMT), accumulator, and so on. Control volumes are collected by flow path module, which delivers energy and mass from one control volume to another with no mass and energy on itself. For China SMR, the riser and downcomer are similar to the hot and cold leg of traditional PWR. Hence, we can use the experience of traditional PWR directly. There are four reactor coolant pumps and 16 stream generators in the vessel. Therefore, these stream generators (SG) should be divided into four groups in order to correspond to the four coolant pumps. For every primary loop, the coolant flow through their respective SGs and coolant pumps and then merge into the same downcomer. Two core makeup tanks are modeled as control volumes and divided into four pipelines as the core makeup water. The pressure balance pipeline is injected into the middle annular of the reactor pressure vessel (RPV). The trip valves are installed on the pipeline between the CMT, and the RPV is used to turn on the CMT. The accumulator is also divided into four pipelines and controlled by check valves. The accumulator shares the same direct injection pipeline with the CMT, which makes up water for primary loop. Relief valves of stage 1 and stage 2 automatic pressure relief system (ADS) are installed on the pipeline between the top of pressurizer and pressure relief valve. The stage-3ADS is installed on the pressurizer wave pipe. When the relief valves of the stage-3 ADS are opened, primary pressure is fast balanced to containment pressure. The stage- 4 ADS is installed on the pressurizer surge pipeline. For this system model, the secondary side of SG is modeled as 3 control volume from top to the bottom of the SG heat exchanger tube. The secondary side of the SG's feedwater is modeled as a mass source which may be prescribed in using control functions. Containment environment is modeled as control volumes, which includes upper ring cavity, lower ring cavity, and several compartments.

\section{Nodalization of Core}

In the Core Package (COR) of MELCOR code, the core region (including the reactor core and lower plenum, two control volume) can be divided into some more detailed cells, as shown in Figure 3. The core region is axially divided into 14 nodes and radially divided into 4 rings. The core activity area contains the node 4 to node 3 , and node 1 to node 3 belongs to the lower plenum area. Node 14 is the core upper inactive area. The Core Package also has the special definition to the lower head. In this article, we divide the lower head into four looped areas. 


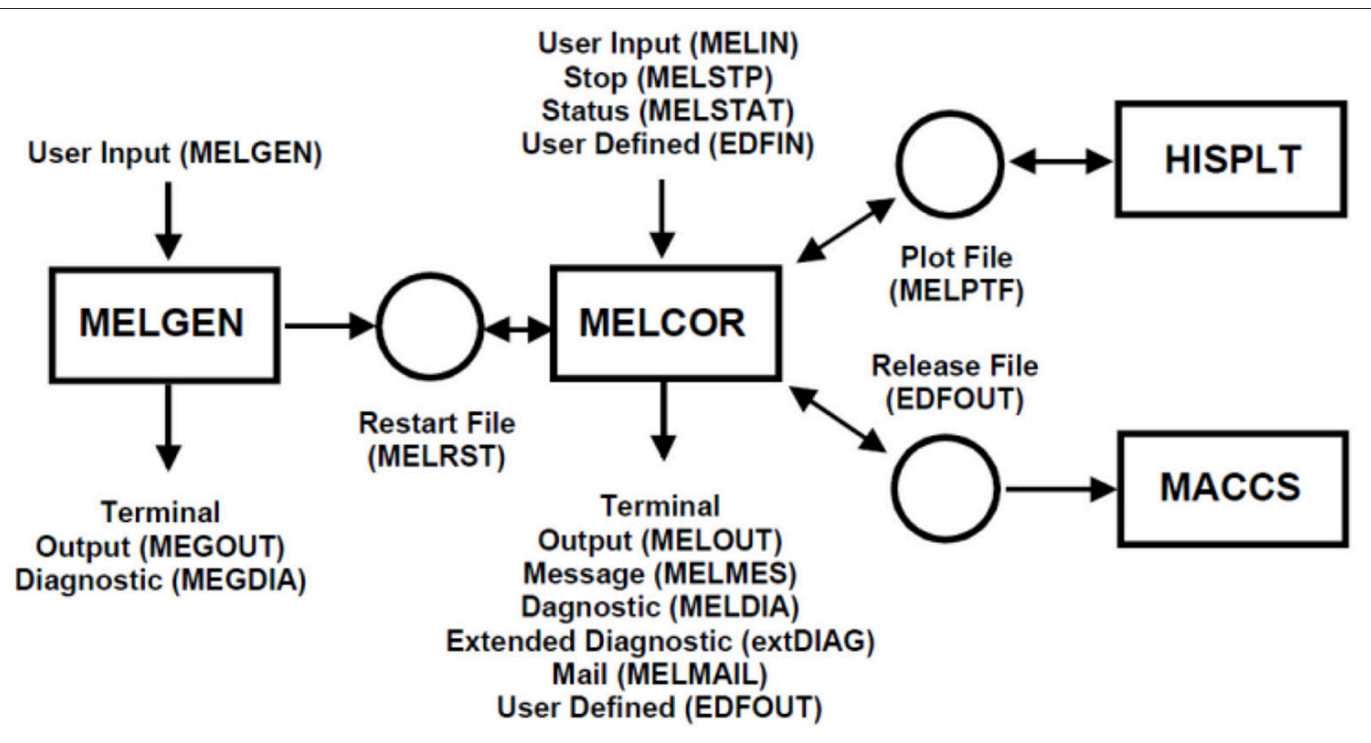

FIGURE 1 | MELCOR code segments.

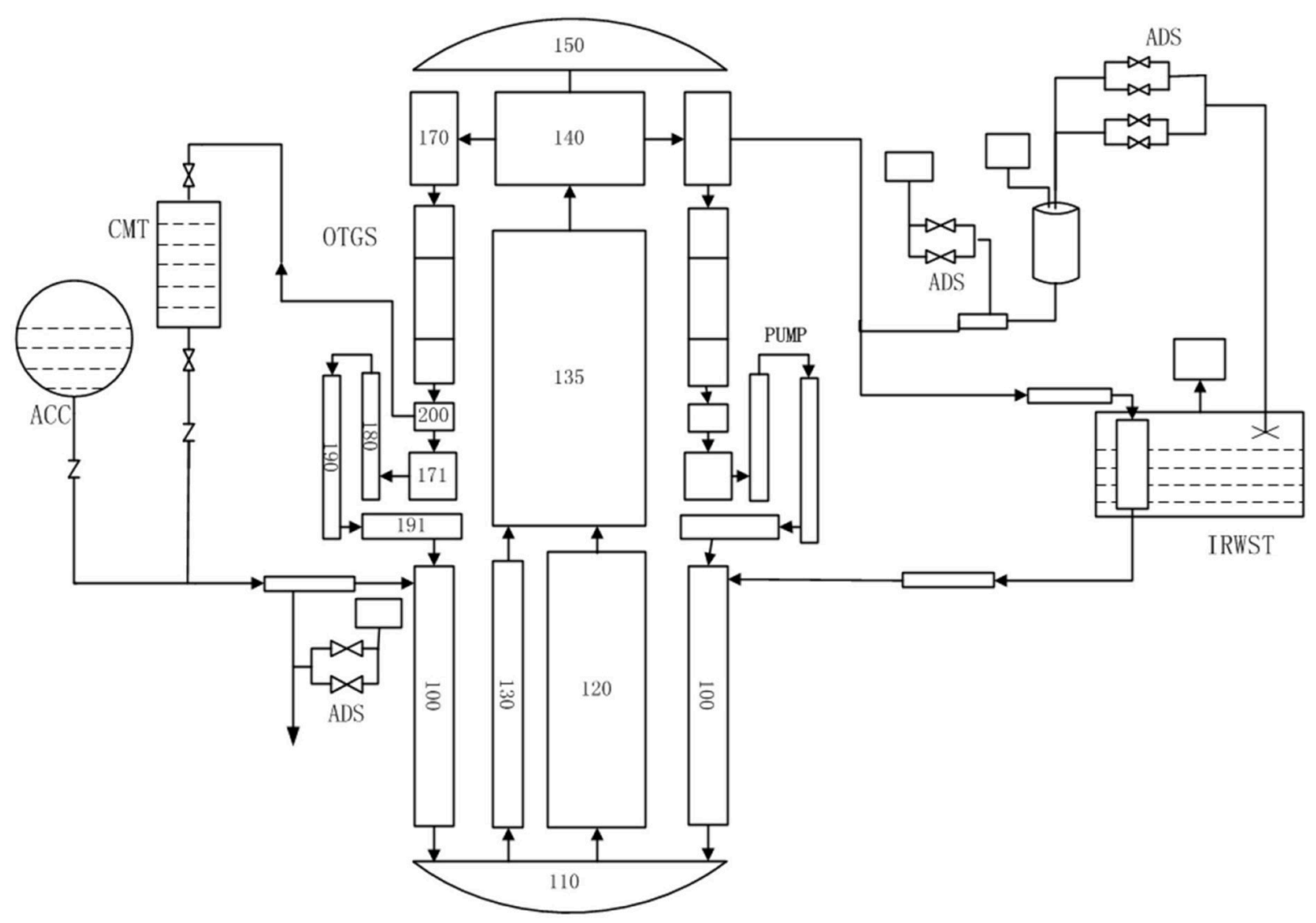

FIGURE 2 | Nodalization of China SMR. 


\section{DESCRIPTION OF ACCIDENT AND ANALYSIS CONDITIONS}

Before we calculate the SBO accident, the steady state analysis was performed for evaluating the SMR MELCOR model. The main parameters of SMR are shown in the following Table 1.

The SBO accident process of SMR is simulated by MELCOR code and the whole process from the accident happened to the corium drop into the cavity is analyzed, especially the

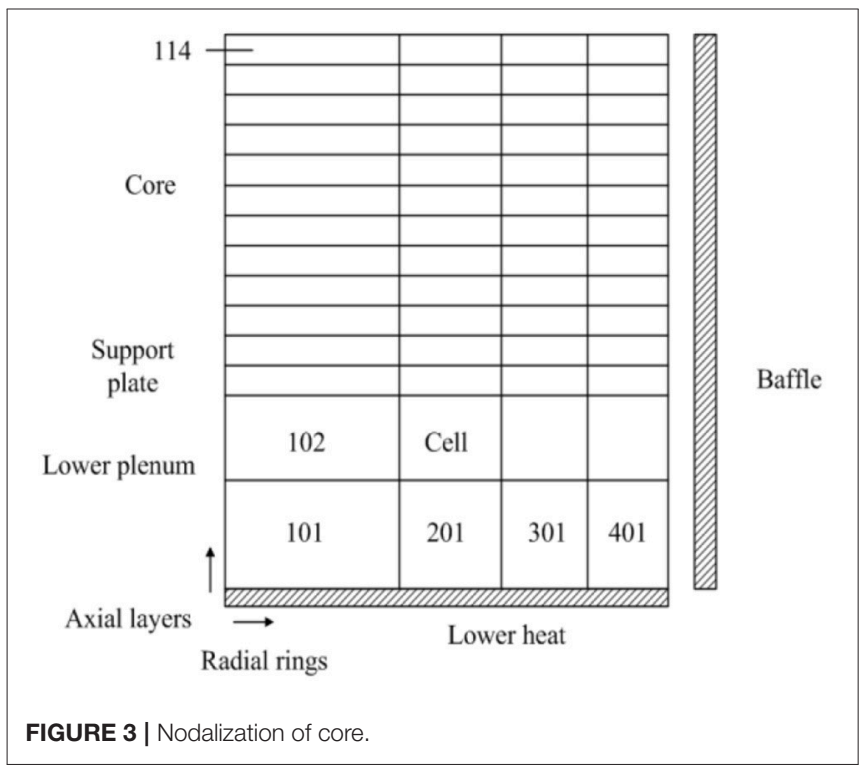

TABLE 1 | The main parameter of SMR.

\section{key parameters}

Core inlet temperature $(\mathrm{K})$

Core outlet temperature $(\mathrm{K})$

Reactor pressure (MPa)

Core flow rate $(\mathrm{kg} / \mathrm{s})$

SG outlet temperature (K)

SG outlet pressure (MPa)

SG outlet flow rate $(\mathrm{kg} / \mathrm{s})$

TABLE 2 | Sequence of SBO initiated severe accident.

\begin{tabular}{lc}
\hline Event & Time/s \\
\hline CMT turn on & 2843.2 \\
CMT water level $<67.5 \%$ & 34485 \\
CMT water level <20.0\% & 34670 \\
Beginning of core uncover & 34500.0 \\
Total uncover of core & 58658.8 \\
Start to melt & 39725.0 \\
Start of debris quench & 59702.0 \\
Lower head has failed & 80270.0
\end{tabular}

passive core cooling system for accident mitigation effect of SMR. Before the accident happened ( $0 \mathrm{~s})$, steady state operating conditions are obtained by the calculation for a period of time. After the accident has happened, the primary pump runs down, immediately following the reactor scram, and loss of feedwater occurs. Due to the loss of the hot trap in secondary loop, the temperature and pressure of the primary loop increase. When the pressure exceeds the setting value of the pressure relief valve $(17 \mathrm{MPa})$, the pressure relief valves opens. The coolant escapes through the relief valve gradually, so the core begins to expose at the same time, and the cladding temperature rises. When the fuel cladding temperature rises to $1273.15 \mathrm{~K}$, the cladding fails, then radioactive material leaked out. It gradually began to appear the core melt and collapsed. The process of the SBO accident is analyzed, and the characteristics of passive core cooling system (PXS) are also analyzed during the accident process.

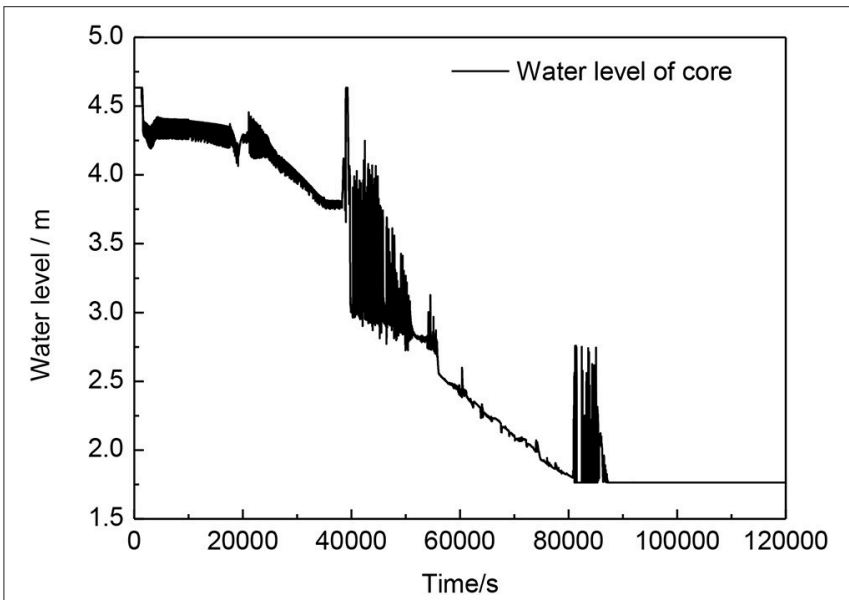

FIGURE 4 | Water level of core.

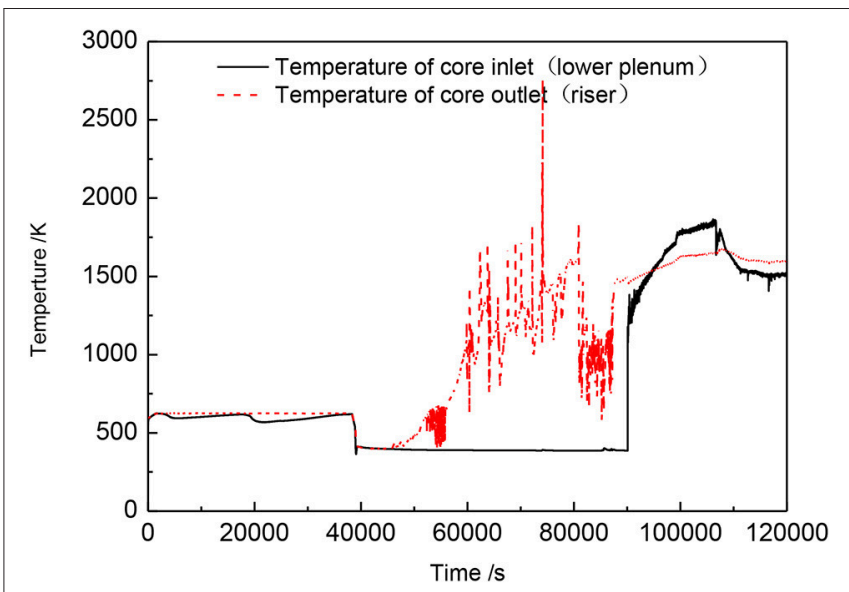

FIGURE 5 | Temperature of core inlet and outlet. 


\section{RESULTS AND DISCUSSIONS}

In severe accident analysis, reactor core thermal hydraulic response directly affects the safety of the reactor, and it is critically important in formulating the corresponding severe accident management strategy. The coolant flows through the lower plenum, and then it is divided into two parts in the core. The main part flows through the active core directly, and the other through the core bypass. Once the reactor shuts down, the coolant pump starts running down, and the cooling of core only relies on the natural circulation. When the natural circulation flow rate decreases, the pressure and temperature of the core increases, and when they get the set value, the pressure relief valve will be triggered to open. Table 2 lists the time sequence of SBO-initiated severe accident for small modular reactor.

As shown in Figure 4, the water level remains volatile at $4.3 \mathrm{~m}$ about $20,000 \mathrm{~s}$. It means that the effective cooling is provided through the new nature circulation created by CMT and lasts a long time. With the continuous natural circulation, the temperature of CMT rises gradually, and the water level begins to drop. When the valves of ADS open, the coolant and vapor are released from the primary system. The water level of the core starts to fall. The active core region is flooded underwater until 38,540 s(as shown in Figure 5), and then the temperature of the core outlet begin to rise.

The coolant mass flow rate of core flow channel and the accumulative coolant quality in core inlet are shown in Figure 6 (before the transient accident, there are 5,000 s calculation for steady state). Hence, the coolant cooling capacity for core is gradually losing with curve declining in the figure.

In order to accurate the analysis of the process and consequences of severe accident, the present study carried out a detailed research in the distribution of transient temperature for core fuel, especially the period that core began to melt. When studying the transient temperature distribution of core fuel, we also took full consideration of the fission products, hydrogen source term, related mechanical deformation, the reactor core structure, and so on.

When a SBO accident happens without any operator intervention, the transient distribution of core fuel temperature is as shown in Figure 7. The number represents the core cell which is according to the axial and radial unit number in MELCOR model, as shown in Figure 3. In the beginning, due to the reactor shutdown, the fuel temperature curve accord with the heat load decline from full power to decay heat. The loss of forced circulation of primary loop does not lead to core fuel temperature rise at the start because the rest of feedwater in the secondary side also can be used as a heat sink to maintain core temperature for a period of time. Then at 2,843s, CMT is triggered (when the pressure of pressurizer is less than a set value), a newly formed natural cycle can maintain the core temperature that does not rise in nearly $10 \mathrm{~h}$. When the water level drops down to the set value (67.5\%), the corresponding ADS system is triggered, and it is at about $34,485 \mathrm{~s}$ as shown in Figure 7. With the opening of ADS system, the water vapor of coolant system is released into the pressurizer relief tank, and therefore, the primary system temperature also has a slight fall. However, as the coolant loses from ADS system, the core begins to uncover since $34,500 \mathrm{~s}$, and the fuel temperature also rises gradually. With the temperature rising, the zirconium cladding interacts with water or steam, and causes strong exothermic reaction. Hence, the related fuel temperature is also surged. As shown in Figure 7, melting begins at the top of fuel element, and then with the collapse, the melt area expands unceasingly. Some temperature oscillation in the lower part of core is mainly

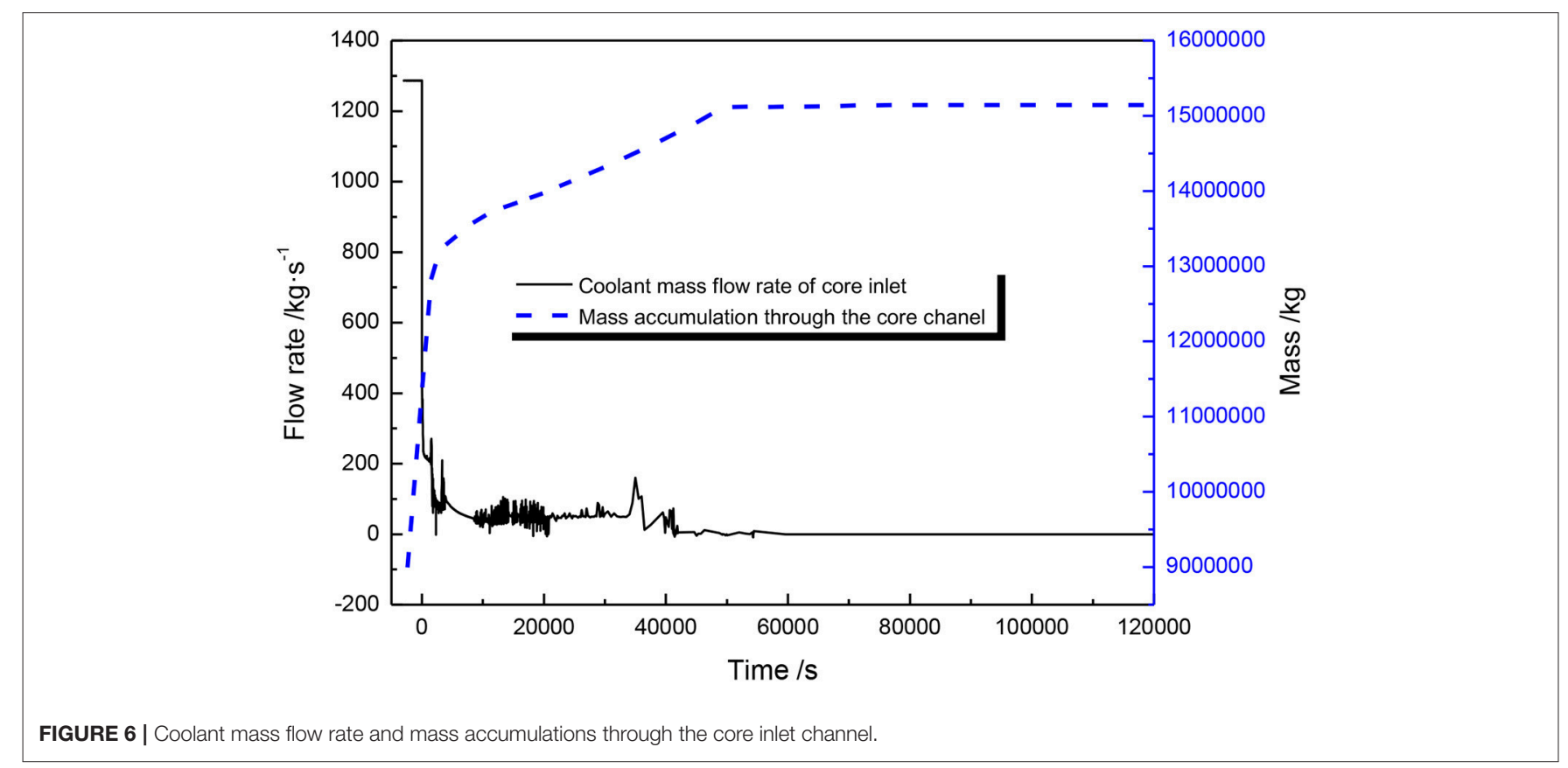



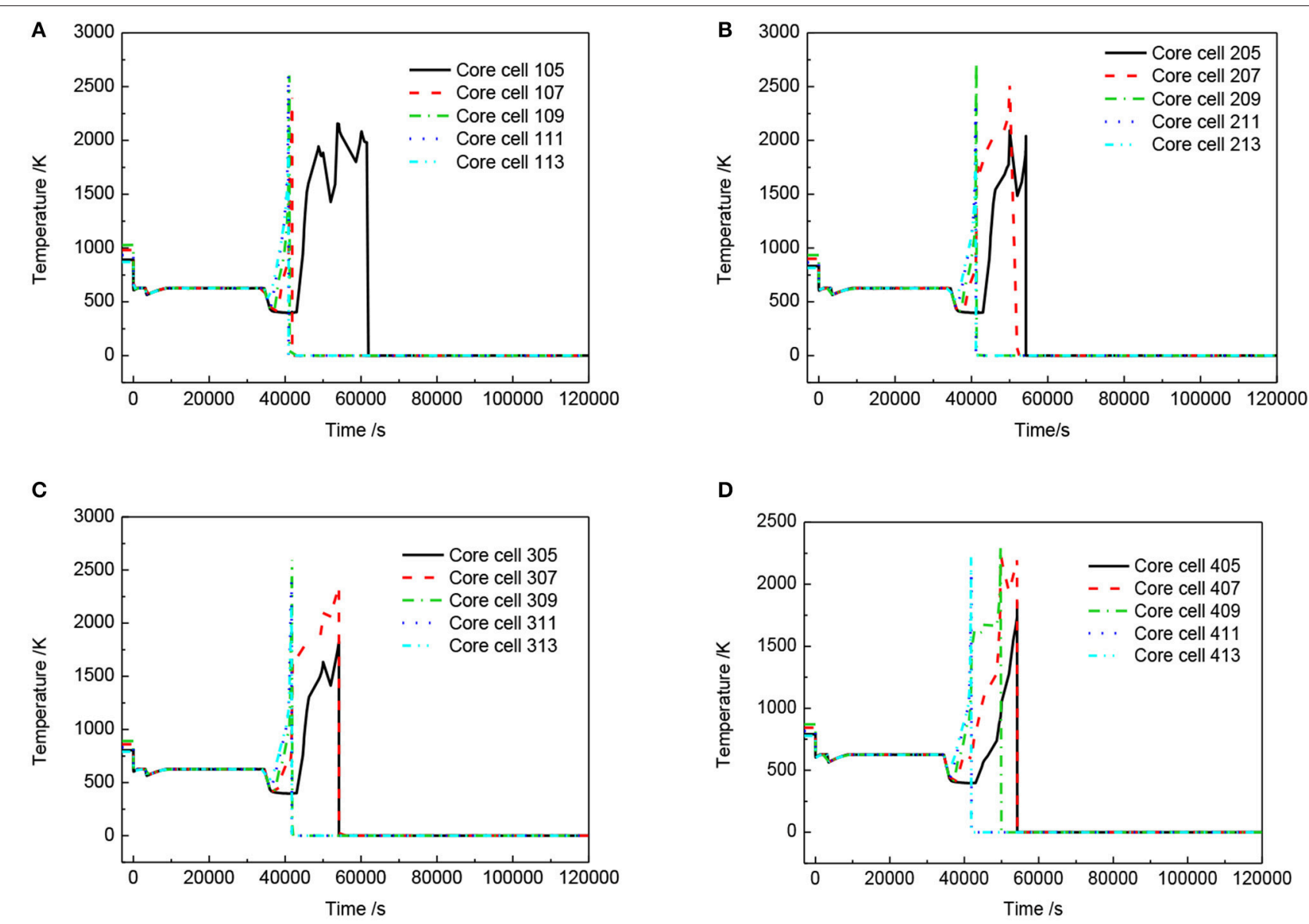

FIGURE 7 | Fuel temperature in core changes over time.

due to the oxidation of cladding and the dynamic migration of fuel.

The fuel temperature distribution shown as Figure $\mathbf{8}$ is for the right half of the core for a number of discreet periods of interest. At the onset of degradation, the high temperature regions are concentrated on the central higher power region, and then move downwards as exothermic reaction abated. At $43,572 \mathrm{~s}$, the temperature of core cell 112 gets to $1,300 \mathrm{~K}$. At about $47,000 \mathrm{~s}$, the high temperature area is at the central part of the reactor core bottom.

In the process of severe accident, it can produce large amounts of hydrogen. These large amounts of hydrogen will be a serious threat for the integrity of reactor containment, so the production rate of hydrogen in core and the spread of hydrogen in containment need to be focused.

With the core uncovering, the coolant in primary loop gradually evaporates. The heat transfer performance is poor between the fuel and the steam. Therefore, fuel temperature rises rapidly. When the temperature exceeds $1,300 \mathrm{~K}$, the zirconium claddings begin to fail and release a lot of heat, which will aggravate the melt of reactor core. The quality of hydrogen produced by core is shown in Figure 9. Between 4,000 and $8,000 \mathrm{~s}$, due to the cladding failure, the interaction of zirconium-water produces large amounts of hydrogen. The peak of hydrogen quality change rate also appears at about 40,000 s. At $80,270 \mathrm{~s}$, due to the failure of the lower head, the hydrogen releases into the containment, and the hydrogen quality in primary loop levels off.

The hydrogen mass change in containment is shown in Figure 10. Due to the opening of ADS system, when the hydrogen mass production rate gets to the peak in primary loop, the hydrogen will be released into containment through the ADS pipeline, so the time when the hydrogen mass production rate gets to the peak in the containment and in the core is consistent. Before the failure of the lower head, the hydrogen mass production rate is very small. However, as shown in Figure 11, continuing with time, the hydrogen quality will continue to accumulate, and it will be a great threat to the integrity of the containment vessel.

\section{CONCLUSIONS}

This paper comprehensively analyzed the SBO severe accident through modeling a complete small modular reactor. The calculation results show that with the gradual development of accident process, severe accident will happen eventually. The 

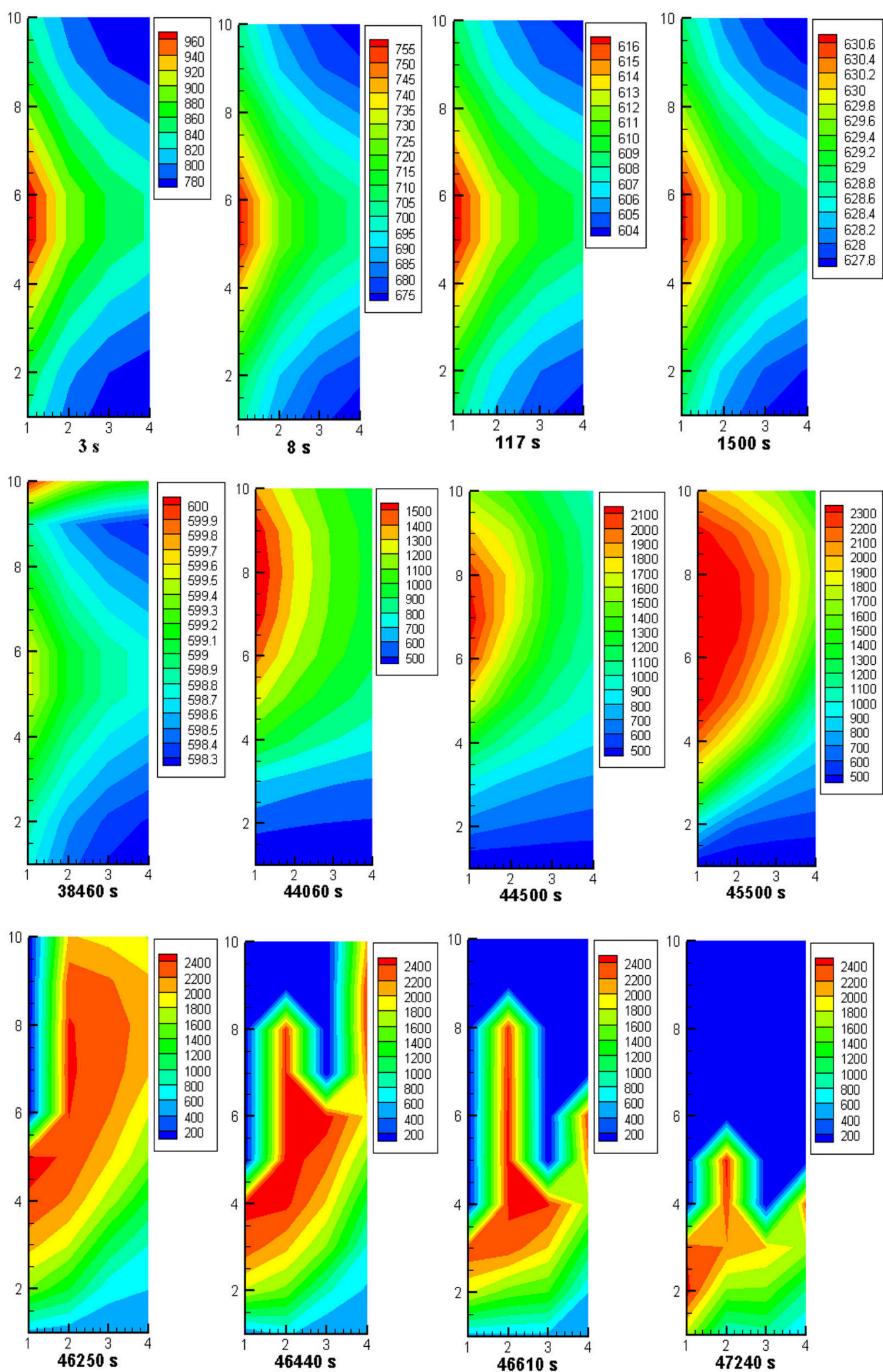

FIGURE 8 | Temperature distribution nephogram. 


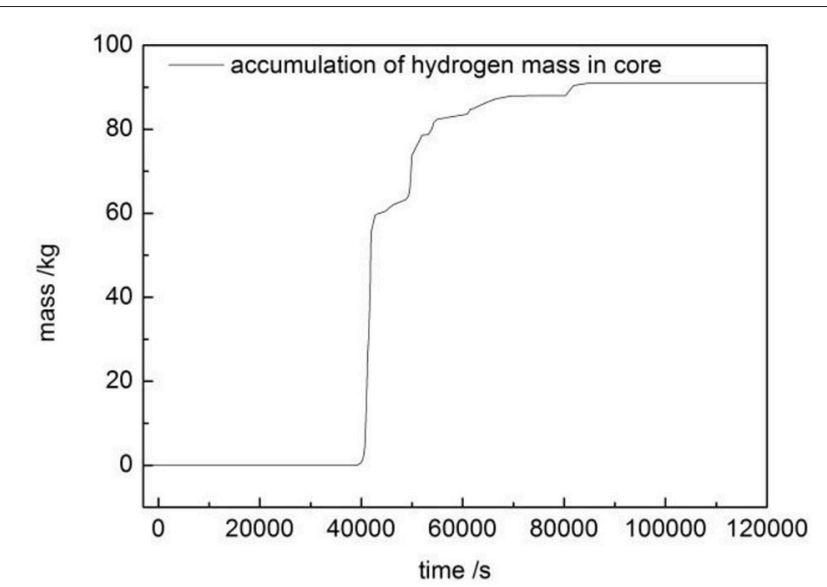

FIGURE 9 | Accumulation of hydrogen mass in core.

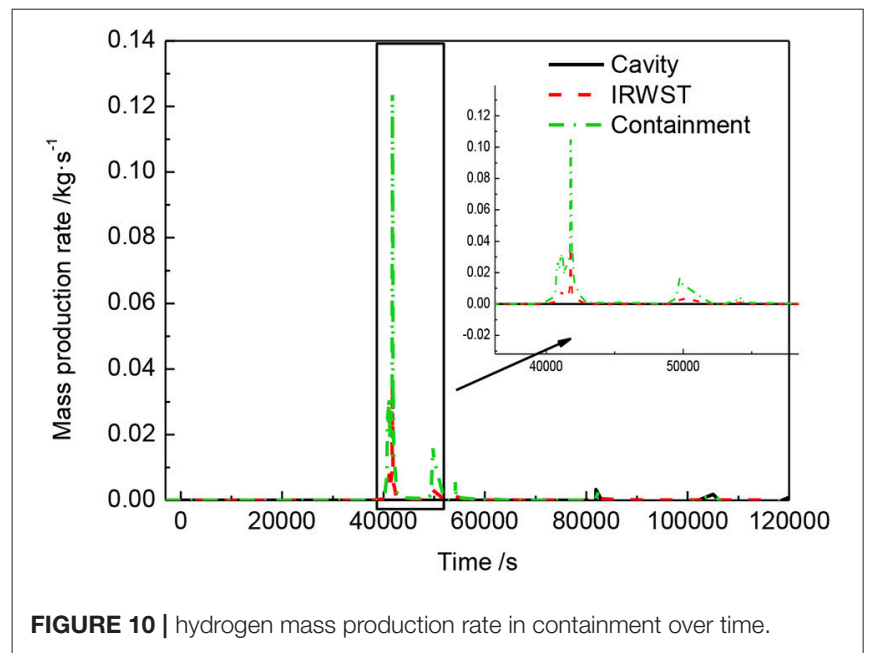

\section{REFERENCES}

Bae, K. H., Kim, H. C., Chang, M. H., and Sim, S. K. (2001). Safety evaluation of the inherent and passive safety features of the smart design. Ann. Nucl. Energy 28, 333-349. doi: 10.1016/S0306-4549(00)00057-8

Carelli, M. D. (2003). IRIS: a global approach to nuclear power renaissance. $\mathrm{Nucl}$. News 46, 32-42.

Carelli, M. D., Conway, L. E., Oriani, L., Petrović, B., Lombardi, C. V., Ricotti, M. E., et al. (2004). The design and safety features of the IRIS reactor. Nucl. Eng. Des. 230, 151-167. doi: 10.1016/j.nucengdes.2003.11.022

Chang, M. H., Sim, S. K., and Lee, D. J. (2000). SMART behavior under over-pressurizing accident conditions. Nucl. Eng. Des. 199, 187-196. doi: 10.1016/S0029-5493(99)00068-0

Fetterman, R. J., Harkness, A. W., Smith, M. C., and Taylor, C. (2011). "An overview of the westinghouse small modular reactor," in ASME 2011 Small Modular Reactors Symposium (Washington, DC: American Society of Mechanical Engineers), 75-82.

Gauntt, R., Cole, R., Erickson, C., Gido, R., Gasser, R., Rodriguez, S., et al. (2000a). MELCOR Computer Code Manuals, Vol. 1:Primer and Users'Guide. Albuquerque, NM: Sandia National Laboratories.

Gauntt, R., Cole, R., Erickson, C., Gido, R., Gasser, R., Rodriguez, S., et al. (2000b). MELCOR Computer Code Manuals, Vol. 2:Reference Manuals. Albuquerque, NM: Sandia National Laboratories.

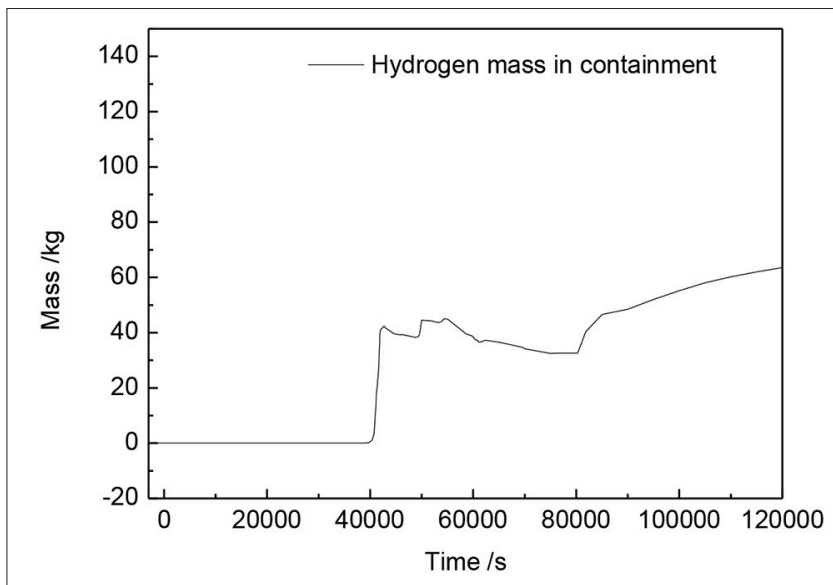

FIGURE 11 | Hydrogen mass in containment over time.

RPV fail at about $80270.0 \mathrm{~s}$, and then inevitably containment failure accident happened. The detailed thermal hydraulic model of core can accurately evaluate the reactor core melting process and predict the radioactive source term. The intense interaction between melt and water in lower plenum caused the pressure vessel failure. The production and accumulation of hydrogen may result in containment failure. Hence, in the subsequent research work, the study may extend to sensitivity analysis of hydrogen, which will be helpful to analyze the severe accident mitigation of small modular reactor.

\section{AUTHOR CONTRIBUTIONS}

SY: Thermal analysis and paper writing; YaT, HF and YeT: Calculation results review; SQ, WH and ZC: Paper writing guidance.

Gauntt, R. O., Cole, R., Hodge, S., Rodriguez, S., Sanders, R., Smith, R., et al. (1998). MELCOR Computer Code Manuals. Rockville, MD: Division of Systems Technology, Office of Nuclear Regulatory Research, US Nuclear Regulatory Commission.

Halfinger, A. J., and Haggerty, D. M. (2012). The B\&W mPower ${ }^{\mathrm{TM}}$ scalable, practical nuclear reactor design. Nucl. Technol. 178, 164-169. doi: 10.13182/N.T.11-65

Ingersoll, D., Houghton, Z., Bromm, R., and Desportes, C. (2014). "Integration of nuscale SMR with desalination technologies," in ASME 2014 Small Modular Reactors Symposium (New York, NY: American Society of Mechanical Engineers), V001-V009.F.

Johnson, R., Pottorf, J., Leonard, M., Modarres, M., Corradini, M., Dhir, V., et al. (2009). "Severe accident prevention and mitigation features of the NuScale PWR design," in Proceedings ANS Winter Meeting (Orlando, FL), 15-19.

Kim, K. M., Lee, B. I., Cho, H. H., Park, J. S., and Chung, Y.-J. (2011). Numerical study on thermo-hydrodynamics in the reactor internals of SMART. Nucl. Eng. Des. 241, 2536-2543, doi: 10.1016/j.nucengdes.2011.04.032

Ricotti, M., Cammi, A., Cioncolini, A., Lombardi, C., Cipollaro, A., Orioto, F., et al. (2002). Preliminary Safety Analysis for the IRIS Reactor. New York, NY: The ASME Foundation, Inc.

Shropshire, D. (2011). Economic viability of small to medium-sized reactors deployed in future European energy markets[J]. Prog. Nucl. Energy 53, 299-307. doi: 10.1016/j.pnucene.2010.12.004 
Wang, J., Tian, W., Zhang, Y., Chen, L., Li, L., Zhang, L., et al. (2014).The development of module in-vessel degraded severe accident analysis code MIDAC and the relevant research for CPR1000 during the station blackout scenario. Prog. Nucl. Energy 76, 44-54. doi: 10.1016/j.pnucene.2014.05.015

Yin, S., Gao, L., Tian, W., Zhang, Y., Qiu, S., and Su, G. (2014). "Loss-of-flowaccidents (Lofa) study for 100 MW IPWR[C]," in 22nd International Conference on Nuclear Engineering, ICONE22 (Prague).

Yin, S., Zhang, Y., Tian, W., Gao, X., Qiu, S. Z., and Su, G. (2016). Simulation of the small modular reactor severe accident scenario response to SBO using MELCOR code[J]. Prog. Nucl. Energy 86, 87-96. doi: 10.1016/j.pnucene.2015.10.007
Conflict of Interest Statement: The authors declare that the research was conducted in the absence of any commercial or financial relationships that could be construed as a potential conflict of interest.

Copyright (c) 2018 Yin, Tian, Qiu, Tian, Fang, Huang and Chen. This is an openaccess article distributed under the terms of the Creative Commons Attribution License (CC BY). The use, distribution or reproduction in other forums is permitted, provided the original author(s) and the copyright owner are credited and that the original publication in this journal is cited, in accordance with accepted academic practice. No use, distribution or reproduction is permitted which does not comply with these terms. 